\title{
Correction to: Harmonics, evolutionary generators, DANCE, and HEAR—-functional dimensions
}

\author{
James Nicholas Furze ${ }^{1,2,3}$ (D) El Hassan Mayad ${ }^{2}$
}

Published online: 21 August 2021

(C) Springer-Verlag GmbH Germany, part of Springer Nature 2021

Correction to: Environmental Science and Pollution Research https://doi.org/10.1007/s11356-021-13159-3

Equation (1):

First generation $x_{i}=x_{i}$

Equation (2):

Second generation

$$
\mathrm{x}_{\mathrm{i}}^{\prime}=\mathrm{x}_{\mathrm{i}} \mathrm{w}_{\mathrm{i}} / \overline{\mathrm{w}}
$$

Equation (3)

Third generation

$$
\mathrm{x}_{\mathrm{i}}^{\prime \prime}=\mathrm{x}_{\mathrm{i}}^{\prime} \mathrm{w}_{\mathrm{i}} / \overline{\mathrm{w}}
$$

$\Delta \mathrm{x}_{\mathrm{i}}=\mathrm{x}_{\mathrm{i}}{ }^{\prime} \mathrm{x}_{\mathrm{i}}$

$\mathrm{x}_{\mathrm{i}} \mathrm{w}_{\mathrm{i}} / \overline{\mathrm{w}}-\mathrm{x}_{\mathrm{i}}$

$\mathrm{x}_{\mathrm{i}}\left(\mathrm{w}_{\mathrm{i}} / \overline{\mathrm{w}}-1\right)$

$$
\begin{aligned}
& \Delta \mathrm{x}_{\mathrm{i}}=\mathrm{x}_{\mathrm{i}}\left(\mathrm{w}_{\mathrm{i}} / \overline{\mathrm{w}}-1\right) \\
& F_{i} \leq j \sum_{j=1}^{n} M_{j} B_{j i},(i=1, \cdots n)
\end{aligned}
$$

Equation (11):

$\phi G_{u}=(-\log G u)^{\Theta G_{u}}$

$G$ is normal font, italic; $u$ is italic, subscript; $-\log$ is normal font; $G u$ is italic; ${ }^{\Theta G}$ is italic, superscript, ${ }^{u}$ is italic, superscript; brackets are not italic.

$H\left(x_{1}, \cdots, x_{n}\right)=C\left(F_{1}\left(x_{i}\right), \cdots, F_{n}\left(x_{n}\right)\right)$

Publisher's note Springer Nature remains neutral with regard to jurisdictional claims in published maps and institutional affiliations.

The online version of the original article can be found at https://doi.org/ 10.1007/s11356-021-13159-3

James Nicholas Furze

jamesfurze@hotmail.com; james.n.furze@gmail.com

1 Royal Geographical Society (with the Institute of British Geographers), 1 Kensington Gore, SW7 2AR London, UK

2 Laboratory of Biotechnology and Valorization of Natural Resources, Faculty of Sciences of Agadir, Department of Biology, Ibn Zohr University, BP 1806, 8000 Agadir, Morocco

3 Control and Systems Engineering Department, University of Technology, Alsinaah Street, P.O. Box: 19006, Postal Code: 10066 Baghdad, Iraq 


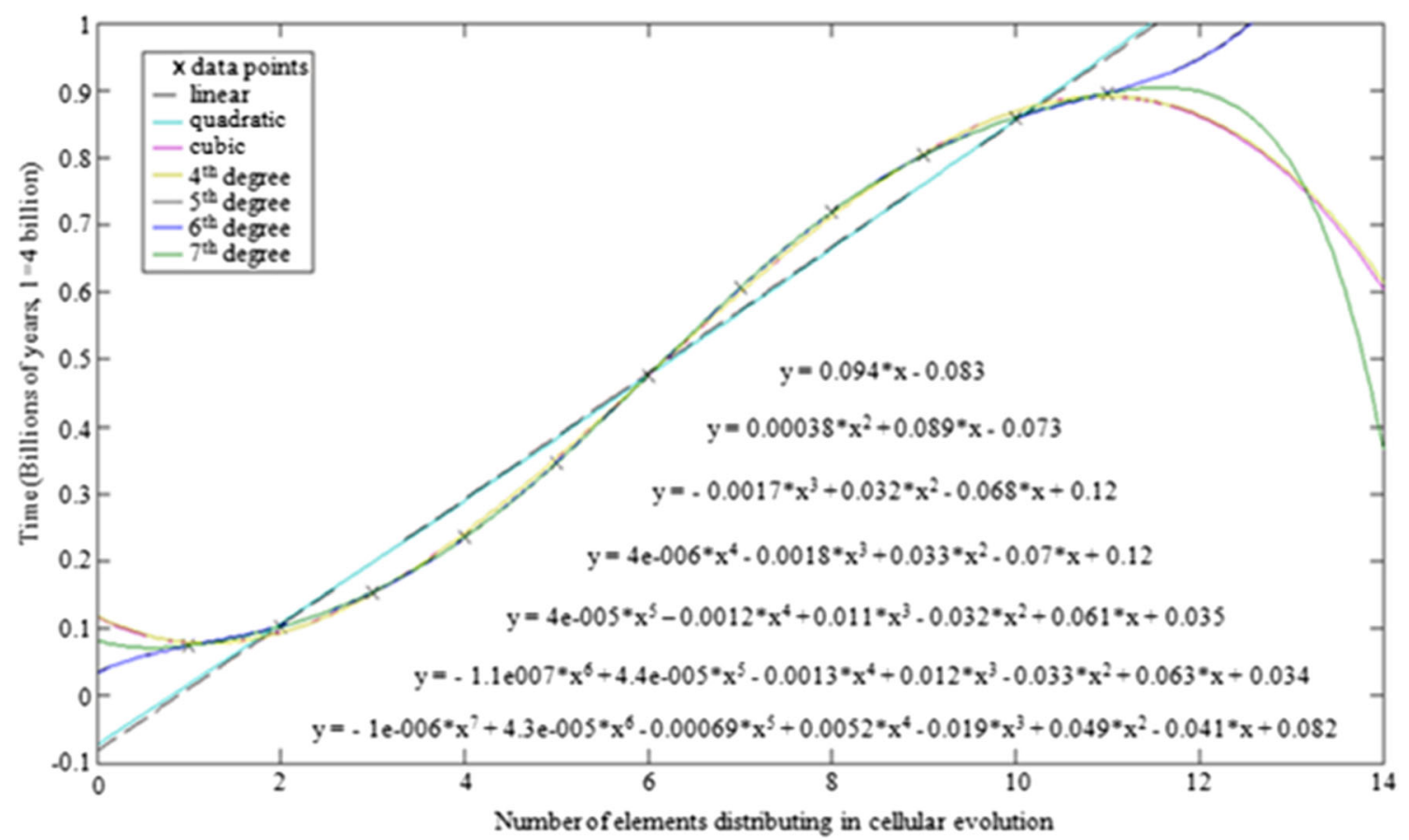

Fig. 2 